\title{
AN INFLUENCE OF THE GEOMETRICAL NONLINEARITY OF A FRAME COLUMN OF FLAT FRAME TYPE $\Gamma$ SUBJECTED TO THE FOLLOWER FORCE DIRECTED TOWARDS THE POSITIVE POLE ON ITS STABILITY
}

\author{
Janusz Szmidla, Justyna Wiktorowicz \\ Institute of Mechanics and Fundamentals of Machinery Design \\ Czestochowa University of Technology \\ Częstochowa, Poland \\ szmidla@imipkm.pcz.pl,wiktorowicz@imipkm.pcz.pl
}

\begin{abstract}
The results of the theoretical and numerical research for the purpose of designation of local and global instability areas of a rectangular frame with a geometrically nonlinear frame column subjected to the follower force directed towards the positive pole are presented in this work. Taking into consideration the total potential energy of an analysed system, the equations describing transverse and longitudinal movements and the boundary conditions necessary for the problem solution are formulated. On the basis of the static criterion of the loss of stability, the influences of the variable flexural stiffness of the system and the geometrical and physical parameters of the flat frame on the value of the bifurcation load are obtained. The results of numerical computations are compared with appropriate values of critical load of the comparative system.
\end{abstract}

Keywords: stability, slender systems, bifurcation load

\section{Introduction}

The issue of the stability of flat frame has been discussed in various studies. Taking into account criterions of the loss of stability (the energetic method and the kinetic criterion) [1], extensive theoretical and numerical studies were conducted. The research resulted in establishing the values of a critical load parameter of considered systems.

The stability of flat frames was examined due to the type of external load: Euler's load [2], Beck's load [3], Reut's load [4] and Tomski's load (a specific load) [5]. An initial imperfections of systems in the form of eccentric application of force [6], a rigidity of structural nodes connecting particular elements [7] or an elasticity of mounting [8] have been also considered in the problem of flat frame stability. Additionally, an influence of the imperfection of a right angle of system on its stability was analysed [9]. 
The issue of local and global instability concerns geometrically nonlinear models [10] of slender elastic systems and is the result of the comparison analysis of values of the bifurcation load parameter of a geometrically nonlinear column and critical load parameter of an appropriate linear column. The value of the bifurcation load, at which the loss of a rectilinear form of the static equilibrium has been obtained for a geometrically nonlinear column, was determined as a function of coefficient of the flexural stiffness asymmetry of particular rods of the system [5].

\section{The physical model of the system}

The model of a geometrically nonlinear flat $\boldsymbol{\Gamma}$ frame subjected to the follower force directed towards the positive pole [5] is presented in Figure 1. A frame column is built of two rods of the flexural stiffness $(E J)_{11}$ and $(E J)_{21}$ and a frame bolt is made of a rod of the flexural stiffness $(E J)_{2}$. Total flexural stiffness of each rod in the frame column is constant (1). Elements of the considered system have been mounted elastically and the frame bolt is able to move in the longitudinal direction. Rods of the frame column and the frame bolt are connected with a load receiving head by a rigid element (3) with a length of $l_{0}$. The direction of loading force passes through a stationary point $O-$ a centre of the curvature of the loading (1) and receiving (2) heads, described by radius $R$.

Obtained results for the geometrically nonlinear $\Gamma \mathrm{N}$ system are compared to the linear $\Gamma L$ system described in the study [11] (a comparative system):

$$
\sum_{i=1}^{2}(E J)_{i 1}=\text { const. }
$$

\subsection{Designations of systems}

For the presented physical models of a geometrically nonlinear $\Gamma \mathrm{N}$ frame (Fig. 1) and a comparative linear $\Gamma L$ frame [11], the following designations are introduced for taking into account selected values of the abovementioned physical and geometrical parameters. Symbols of the considered frames, as well as their parameters, are shown in Table 1.

Table 1

The designations of the systems

\begin{tabular}{|c|c|c|}
\hline$\Gamma \mathrm{L}\left(\mu_{C}, \mu_{S}, l_{r}, \varphi, c_{1}{ }^{*}, c_{2}{ }^{*}\right)$ & $\Gamma \mathrm{N}\left(\mu_{C}, \mu_{S}, l_{r}{ }^{*}, \varphi, c_{1}{ }^{*}, c_{2}{ }^{*}\right)$ \\
\hline$\mu_{C}=\frac{(E J)_{2}}{\sum_{i=1}^{2}(E J)_{i 1}}, \mu_{S}=\frac{(E J)_{21}}{(E J)_{11}}, \varphi=\frac{l_{2}}{l_{1}}, l_{r}^{*}=\frac{R-l_{0}}{l_{1}}, c_{1}^{*}=\frac{c_{1}\left(l_{1}+l_{2}\right)}{\sum_{i=1}^{2}(E J)_{i 1}}, c_{2}^{*}=\frac{c_{2}\left(l_{1}+l_{2}\right)}{\sum_{i=1}^{2}(E J)_{i 1}}$ & (2-7) \\
\hline
\end{tabular}




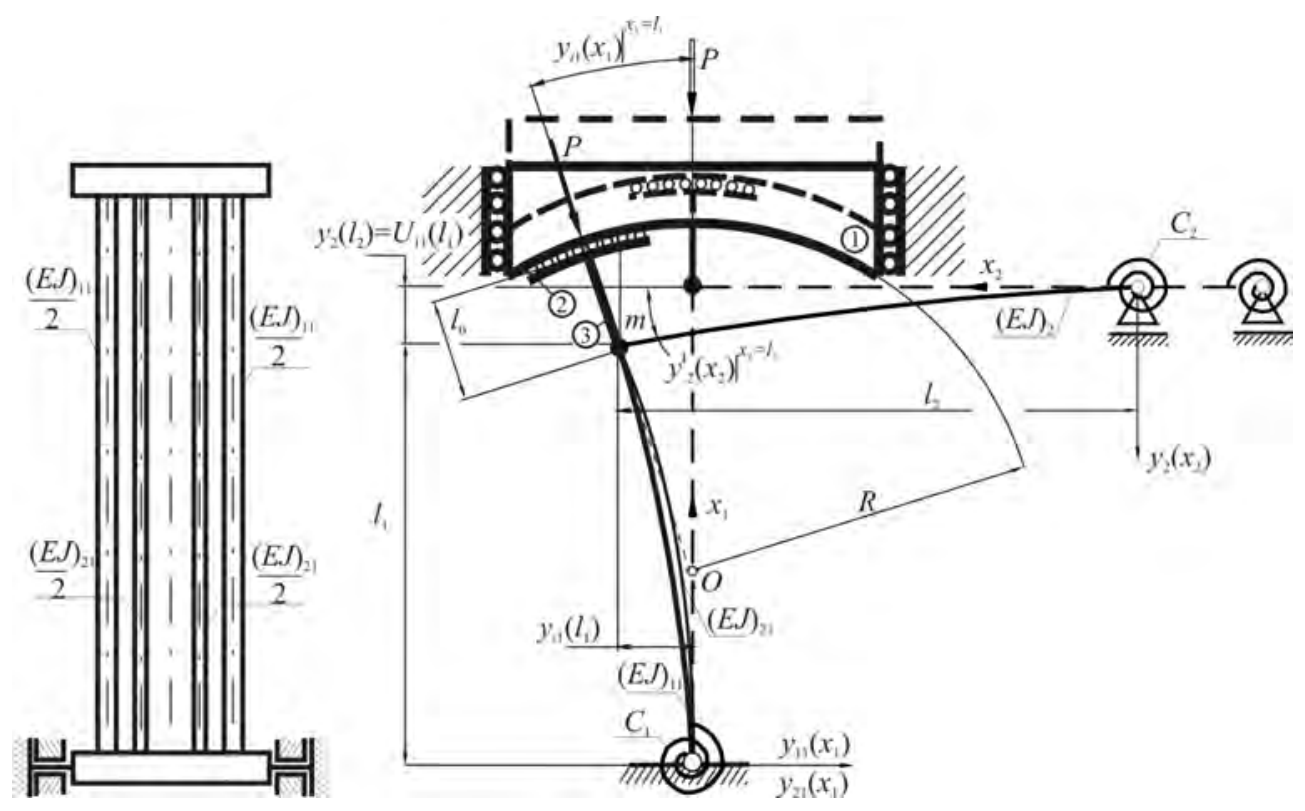

Fig. 1. The flat frame of $\Gamma$ type with a geometrically nonlinear frame column subjected to the follower force directed towards the positive pole $\Gamma \mathrm{N}\left(\mu_{C}, \mu_{S}, l_{r}{ }^{*}, \varphi, c_{1}{ }^{*}, c_{2}{ }^{*}\right)$

\section{The mathematical model}

Taking into account the physical model of a geometrically nonlinear $\Gamma \mathrm{N}$ frame, the components of potential energy are defined. The total potential energy $V$ consists of energies of the bending elasticity, internal forces in the particular rods, action of the external load and the potential energy resulting from the elastic mounting of a frame column and frame bolt:

$$
\begin{aligned}
& V=\sum_{i=1}^{2} \frac{(E J)_{i 1}}{2} \int_{0}^{l_{1}}\left(y_{i 1}^{I I}\left(x_{1}\right)\right)^{2} d x_{1}+\sum_{i=1}^{2} \frac{(E A)_{i 1}}{2} \int_{0}^{l_{1}}\left[U_{i 1}^{I}\left(x_{1}\right)+\frac{1}{2}\left(y_{i 1}^{I}\left(x_{1}\right)\right)^{2}\right]^{2} d x_{1}+ \\
& +\frac{(E J)_{2}}{2} \int_{0}^{I_{2}}\left(y_{2}^{I I}\left(x_{2}\right)\right)^{2} d x_{2}+\frac{P R}{2}\left(y_{11}^{I}\left(l_{1}\right)\right)^{2}-\frac{P l_{0}}{2}\left(y_{11}^{I}\left(l_{1}\right)\right)^{2}+ \\
& \frac{C_{1}}{2}\left(y_{11}^{I}(0)\right)^{2}+\frac{C_{2}}{2}\left(y_{2}^{I}(0)\right)^{2}-P U_{11}\left(l_{1}\right), \quad i=1,2 .
\end{aligned}
$$

The issue of the stability of a geometrically nonlinear frame was solved applying the minimum potential energy principle, which consists of searching for a value of external load at which the potential energy is no longer positively defined the energetic method [1]: 


$$
\delta V=0
$$

where $\delta$ - variation operator.

Taking into account the formula (9), after the prior calculus of variation of potential energy (8), the following equations were obtained:

- equations of the transverse movements:

$$
\begin{aligned}
& (E J)_{i 1} y_{i 1}^{I V}\left(x_{1}\right)+S_{i 1} y_{i 1}^{I I}\left(x_{1}\right)=0, \\
& (E J)_{2} y_{2}^{I V}\left(x_{2}\right)=0, \quad i=1,2 .
\end{aligned}
$$

- equations of the longitudinal movements of the frame column of $\Gamma \mathrm{N}$ system:

$$
U_{i 1}\left(x_{1}\right)=-\frac{S_{i 1}}{(E A)_{i 1}} x_{1}-\frac{1}{2} \int_{0}^{x_{1}}\left[y_{i 1}^{I}\left(x_{1}\right)\right]^{2} d x_{1} .
$$

The geometrical boundary conditions can be written in the following form:

$$
\begin{aligned}
& y_{11}(0)=y_{21}(0)=y_{2}(0)=0, \quad y_{11}^{I}\left(l_{1}\right)=y_{21}^{I}\left(l_{1}\right)=y_{2}^{I}\left(l_{2}\right), \\
& y_{11}^{I}(0)=y_{21}^{I}(0), \quad y_{11}\left(l_{1}\right)=y_{21}\left(l_{1}\right) .
\end{aligned}
$$

A construction solution of loading (1) and receiving (2), (3) heads allows one to determine the following boundary condition:

$$
y_{11}\left(l_{1}\right)=\left(R-l_{0}\right) y_{11}^{I}\left(l_{1}\right)
$$

that take into consideration a linear relation between the deflection and the angle of deflection of the end of the frame column.

Regarding the geometrical boundary conditions in variation of potential energy, missing natural boundary conditions necessary for boundary problem solution may be formulated:

$$
\begin{aligned}
& (E J)_{11} y_{11}^{I I}(0)+(E J)_{21} y_{21}^{I I}(0)-C_{1} y_{11}^{I}(0)=0, \\
& (E J)_{2} y_{2}^{I I}(0)-C_{2} y_{2}^{I}(0)=0, \\
& \sum_{i=1}^{2}(E J)_{i 1} y_{i 1}^{I I I}\left(l_{1}\right)-\frac{1}{R-l_{0}}\left[\sum_{i=1}^{2}(E J)_{i 1} y_{i 1}^{I I}\left(l_{1}\right)+(E J)_{2} y_{2}^{I I}\left(l_{2}\right)\right]=0, \\
& (E J)_{2} y_{2}^{I I I}\left(l_{2}\right)=0, \\
& U_{11}(0)=U_{21}(0)=0, \\
& U_{11}\left(l_{1}\right)=U_{21}\left(l_{1}\right), \quad i=1,2 .
\end{aligned}
$$




\section{The solution of the boundary problem}

The issue of stability has been solved by substituting the equations (27)-(29) (which are the solutions of equations (10) in the boundary conditions (12)-(23)). In this way, a transcendental equation for determining the value of bifurcation force $P_{b}$ has been obtained:

$$
\begin{aligned}
& y_{i 1}(x)=A_{i 1} \sin \left(k x_{1}\right)+B_{i 1} \cos \left(k x_{1}\right)+C_{i 1} x_{1}+D_{i 1}, \\
& y_{2}(x)=A_{2} x_{2}^{3}+B_{2} x_{2}^{2}+C_{2} x_{2}+D_{2}, \quad i=1,2 .
\end{aligned}
$$

\subsection{Results of numerical analysis}

In this work, the values of bifurcation load $P_{b}$ of geometrically nonlinear frame $\Gamma \mathrm{N}\left(\mu_{C}, \mu_{S}, l_{r}{ }^{*}, \varphi, c_{1}{ }^{*}, c_{2}{ }^{*}\right)$ and critical load $P_{k r}$ of linear (comparative) frame $\Gamma \mathrm{L}\left(\mu_{C}, \mu_{S}, l_{r}^{*}, \varphi, c_{1}{ }^{*}, c_{2}{ }^{*}\right)$ have been expressed by dimensionless coefficients described by formulas (30) and (31), respectively:

$$
\lambda_{b}^{*}=\frac{P_{b}\left(l_{1}\right)^{2}}{\sum_{i=1}^{2}(E J)_{i 1}}, \quad \lambda_{c r}^{*}=\frac{P_{k r}\left(l_{1}\right)^{2}}{\sum_{i=1}^{2}(E J)_{i 1}}
$$

The values of critical load parameter $\lambda_{c r}{ }^{*}$ of a linear frame $\Gamma \mathrm{L}$ and bifurcation load parameter $\lambda_{b}{ }^{*}$ of a geometrically nonlinear frame $\Gamma \mathrm{N}$ as a function of coefficient of the flexural stiffness asymmetry of frame column $\mu_{s}$ (3) is presented in Figure 2.

Rods with lower flexural stiffness are responsible for the local loss of the stability. A removal of these rods from the frame column of geometrically nonlinear frame causes a sudden increase in critical load parameter (a transition from point $A_{1}$ to point $A_{2}$ ). Therefore, in the range of the coefficient of the flexural stiffness asymmetry $\mu_{S} \in\left(0, \mu_{g r}\right)$ the local loss of stability occurs. For $\mu_{S}>\mu_{g r}$ the global loss of stability takes place.

Figures 3-5 present a relation of critical load parameter $\lambda_{c r}{ }^{*}$ of a linear $\Gamma L$ frame and the bifurcation load parameter of a geometrically nonlinear $\Gamma \mathrm{N}$ frame in function of the coefficient of the flexural stiffness asymmetry of frame column $\mu_{S}$ for different values of the coefficient of total flexural stiffness asymmetry $\mu_{C}$. Each of the plots shows the results for selected values of loading and receiving heads radius coefficient $l_{r}{ }^{*}$. The obtained results are compared with the bifurcation and critical load of nonlinear column KN (frame column of the $\Gamma \mathrm{N}$ system) and linear column KL (frame column of the $\Gamma \mathrm{L}$ system) presented in work [12]. 


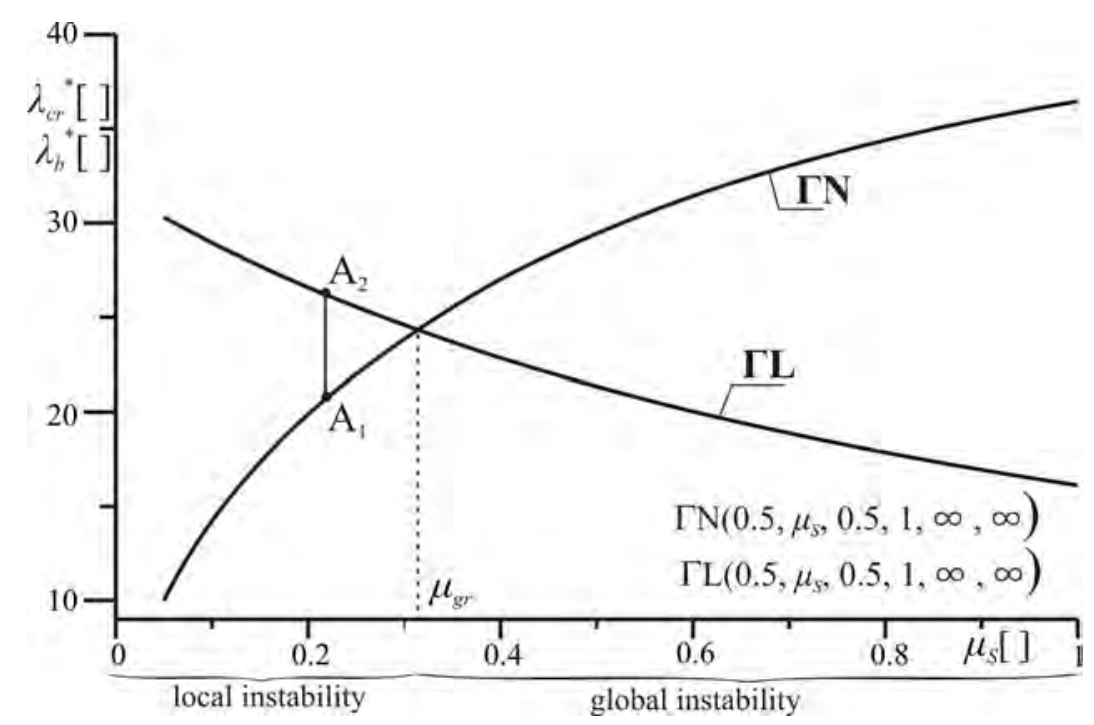

Fig. 2. The values of the critical load parameter $\lambda_{c r}{ }^{*}$ ( $\Gamma \mathrm{L}$ frame) and the bifurcation load parameter $\lambda_{b}{ }^{*}$ ( $\Gamma \mathrm{N}$ frame) in the function of coefficient of the flexural stiffness asymmetry of frame column $\mu_{s}$

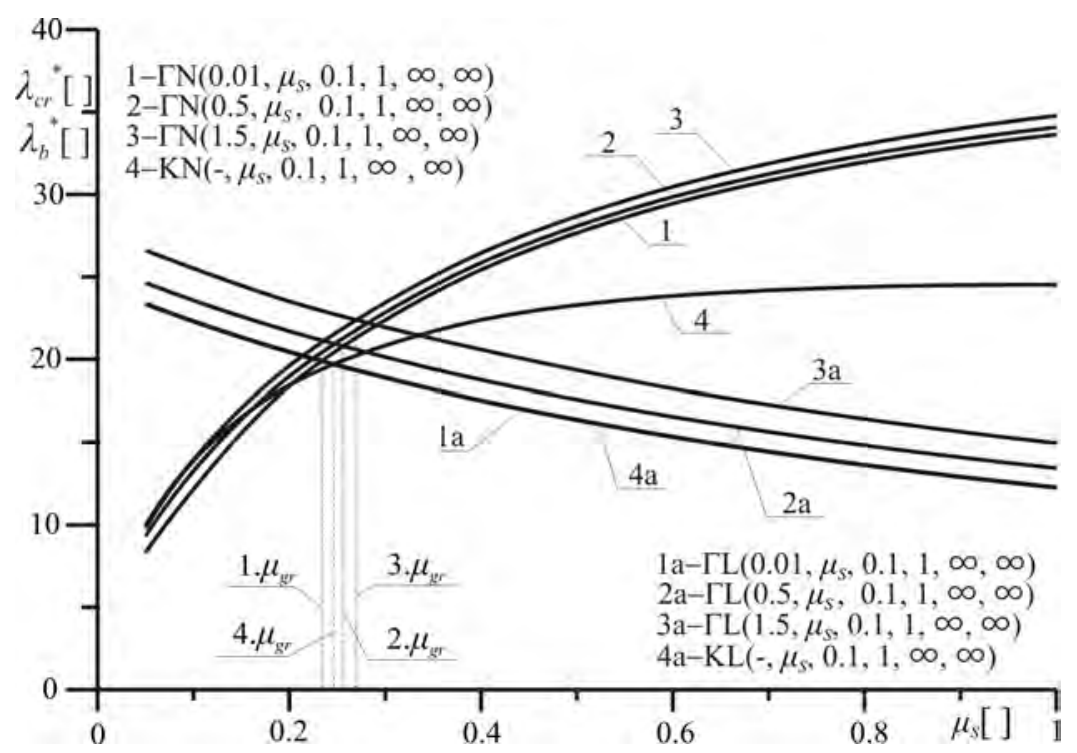

Fig. 3. The critical load parameter $\lambda_{c r}{ }^{*}(\Gamma L$ frame) and the bifurcation load parameter ( $\Gamma \mathrm{N}$ frame) $\lambda_{b}{ }^{*}$ as a function of coefficient of the flexural stiffness asymmetry of frame column $\mu_{s}$ for different values of coefficient of the flexural stiffness asymmetry of total system $\mu_{C}$ 


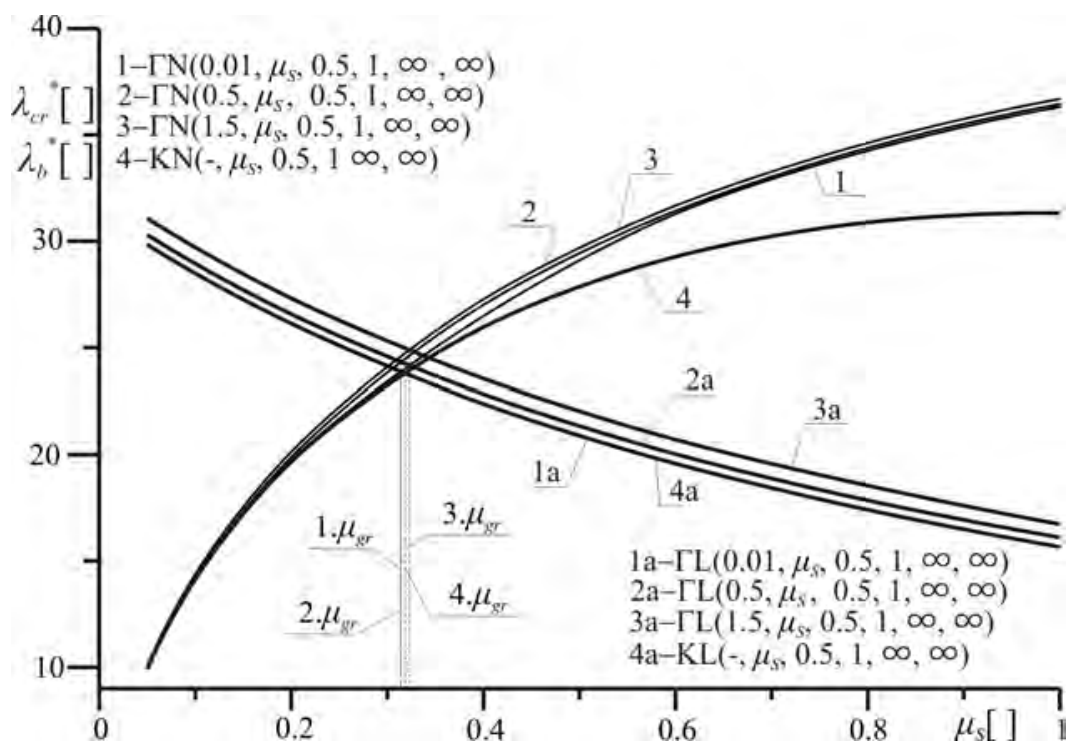

Fig. 4. The critical load parameter $\lambda_{c r}{ }^{*}$ ( $\Gamma \mathrm{L}$ frame) and the bifurcation load parameter ( $\Gamma \mathrm{N}$ frame) $\lambda_{b}{ }^{*}$ as a function of coefficient of the flexural stiffness asymmetry of frame column $\mu_{s}$ for different values of coefficient of the flexural stiffness asymmetry of total system $\mu_{C}$

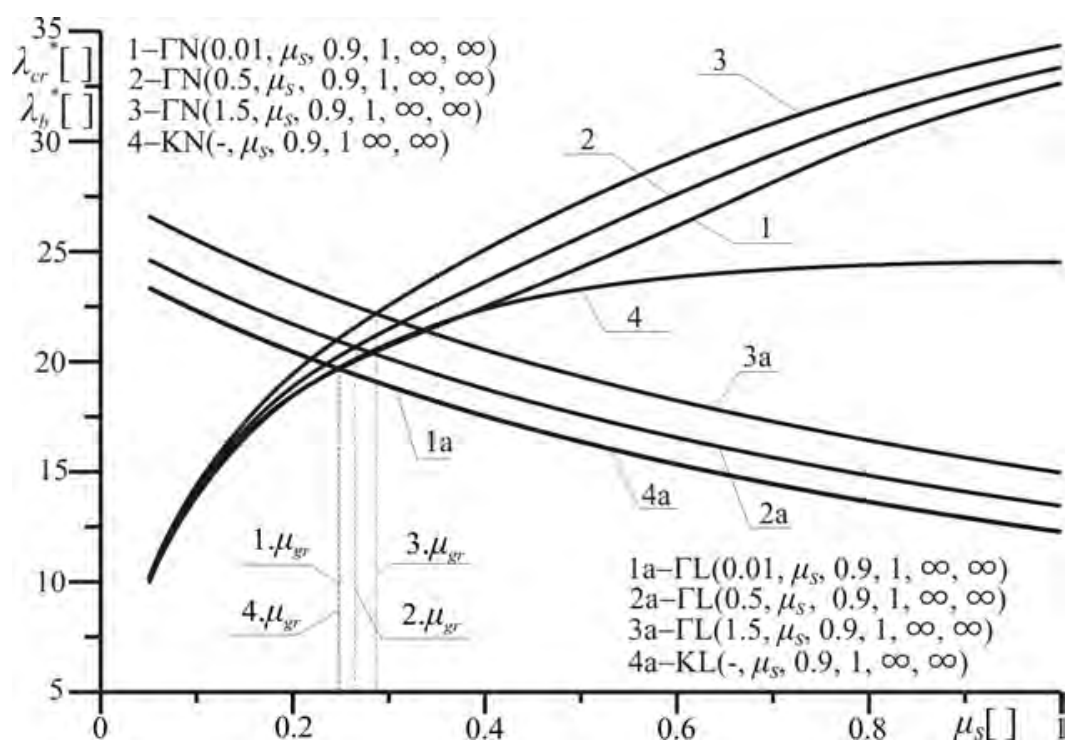

Fig. 5. The values of the critical load parameter $\lambda_{c r}{ }^{*}$ ( $\Gamma \mathrm{L}$ frame) and the bifurcation load parameter $\lambda_{b}^{*}$ ( $\Gamma \mathrm{N}$ frame) as a function of coefficient of the flexural stiffness asymmetry of frame column $\mu_{s}$ for selected values of coefficient of total flexural stiffness asymmetry $\mu_{C}$ 
An influence of total flexural stiffness of the considered system $\mu_{C}$ on the limit value of the coefficient of the flexural stiffness asymmetry of frame column $\mu_{g r}$ of $\Gamma \mathrm{N}$ frame for selected values of coefficient of frame column and bolt mounting rigidity $c_{1}{ }^{*}$ and $c_{2}{ }^{*}$ was shown in Figure 6 . On the basis of the limit value of coefficient of the flexural stiffness asymmetry, the areas of local and global instability were determined. The global loss of stability occurs above the presented curves and the local loss of stability takes place for values below the curves.

In the case of a pinned connection between frame column and frame bolt, the limit value of coefficient of the flexural stiffness asymmetry is constant and independent of total flexural stiffness $\mu_{C}$ of system (Fig. 7).

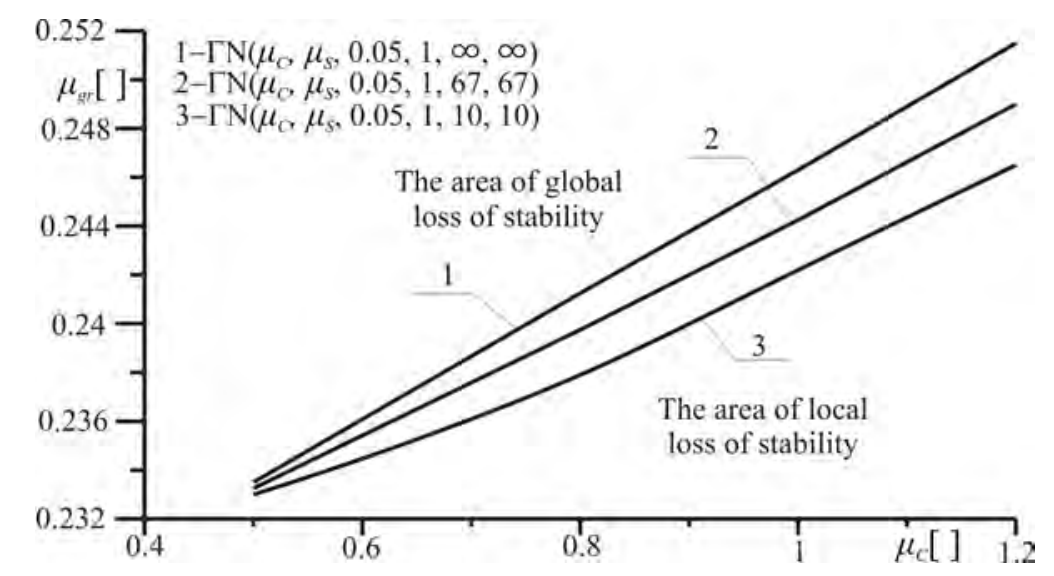

Fig. 6. The influence of coefficient of total flexural stiffness asymmetry $\mu_{C}$ on the limit value of coefficient of the flexural stiffness asymmetry $\mu_{g r}$ of frame column of $\Gamma \mathrm{N}$ system for selected values of the frame column and bolt mounting rigidity coefficients $c_{1}{ }^{*}$ and $c_{2}{ }^{*}$

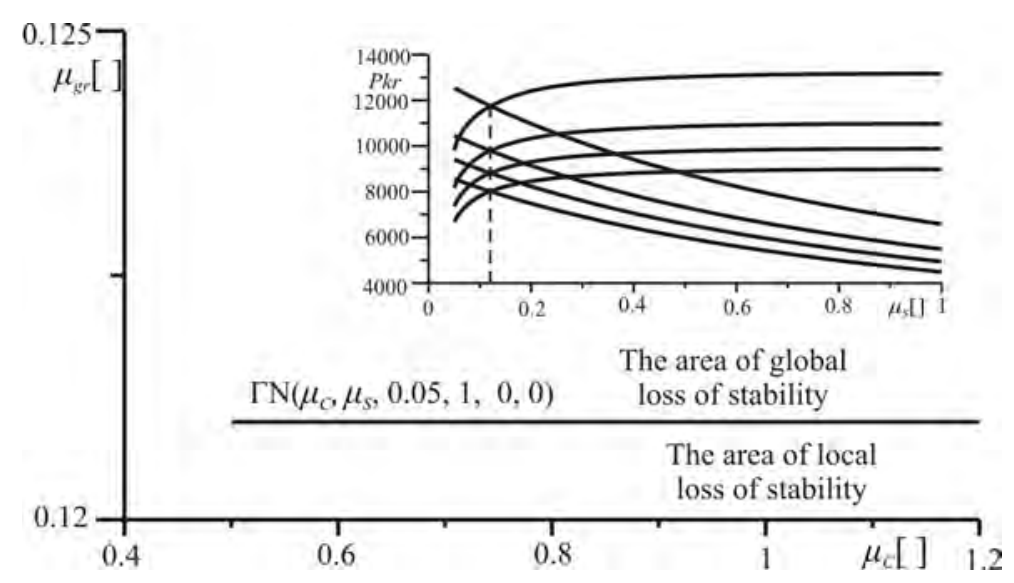

Fig. 7. The influence of coefficient of total flexural stiffness asymmetry $\mu_{C}$ on the limit value of coefficient of the flexural stiffness asymmetry $\mu_{g r}$ of the frame column of $\Gamma \mathrm{N}$ system, where $c_{1}{ }^{*}=0$ and $c_{2}{ }^{*}=0$ 
An influence of parameters describing the geometry of loading head $\left(R\right.$ and $\left.l_{0}\right)$ on the limit value of the coefficient of the flexural stiffness asymmetry $\mu_{g r}$ is shown in Figure 8. On the basis of the abovementioned limit value, the areas of local and global loss of stability were determined. The global instability takes place above the presented curve and the local instability corresponds with values below the curve. It has been proved that the obtained curve for the selected values of mounting rigidity coefficients $c^{*}$ and for the particular value of total flexural stiffness of the system reaches the maximum value for the $l_{r}^{*}$ parameter in the range between 0.5 and 0.7 .

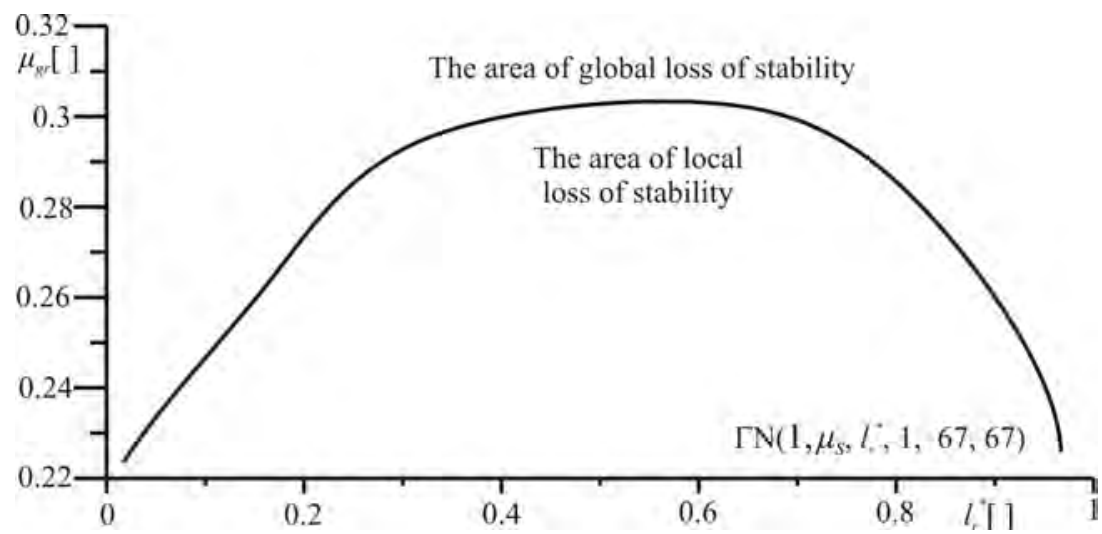

Fig. 8. The influence of the value of loading and receiving heads radius $R$ on the limit value of coefficient of the flexural stiffness asymmetry $\mu_{g r}$

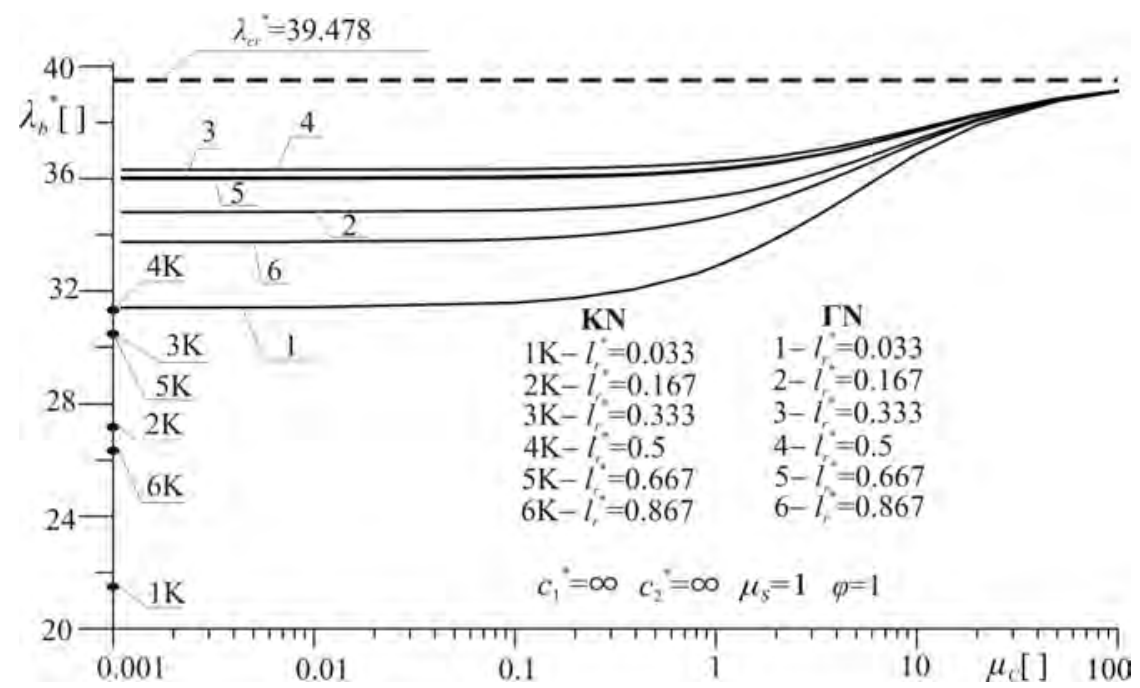

Fig. 9. The values of bifurcation load parameter $\lambda_{b}{ }^{*}$ as a function of coefficient of total flexural stiffness asymmetry $\mu_{C}$ for selected values of radius of loading and receiving heads parameter $l_{r}^{*}$ 
The change of the bifurcation load $\lambda_{c r}{ }^{*}$ as a function of the coefficient of total flexural stiffness asymmetry $\mu_{C}$ for the selected values of loading and receiving heads radius coefficient $l_{r}^{*}$ was presented in Figure 9. With increasing total flexural stiffness $\mu_{C}$ of the analysed system, the bifurcation load of the frame asymptotically approaching the value of the critical load (shown by the dashed line), that corresponds to the column subjected to the particular case of Euler's load [1]. In addition, the values of the bifurcation load of the geometrically nonlinear column (frame column) [12] were marked with points $1 \mathrm{~K}-6 \mathrm{~K}$. The localisation of these points describes an increase in the bifurcation load of the geometrically nonlinear system with extra stiffness in the form of the frame bolt, whose geometry is defined by $\mu_{C}$ parameter.

\section{Conclusions}

A flat frame of type $\Gamma$ with a geometrically nonlinear frame column was presented in this work. Taking into account the total potential energy, the boundary conditions were formulated.

On the basis of the results of numerical analysis of a geometrically nonlinear $\Gamma \mathrm{N}$ frame, an increase in the value of bifurcation load parameter due to the increase of total flexural stiffness $\mu_{C}$ (Figs. 4-6) was noted. Additionally, the bifurcation load parameter reached the maximum value for the radius of loading and receiving heads parameter $l_{r}^{*}=0.5$ in the case of rigid mounting of the frame column and bolt in the model of a geometrically nonlinear $\Gamma \mathrm{N}$ frame subjected to the follower force directed towards the positive pole.

The ranges of local and global loss of stability depend on the value of the coefficient of total flexural stiffness asymmetry and on the geometry of loading head.

\section{Acknowledgments}

The study has been carried out within the framework of project BS/PB-1-1013020/11/P realized at Czestochowa University of Technology.

\section{References}

[1] Tomski L., Szmidla J., Wprowadzenie do problematyki stateczności i drgań swobodnych kolumn, [In:] Drgania i stateczność układów smukłych, ed. L. Tomski, Wydawnictwo Naukowo-Techniczne, Fundacja „Książka Naukowo-Techniczna”, Warszawa 2004.

[2] Leipholz H.H.E., On conservative elastic systems of the first and second kind, Ingenieur-Archiv 1974, 43, 255-271.

[3] Beck M., Die kniclast des einseitig eingespannten tangential gedruckten Stabes, ZAMP 1953, 4, 225-228, 476-477. 
[4] Gajewski A., Życzkowski M., Optimal Structural Design under Stability Constraints, Dordrecht Kluwer Academic Publisher, 1988, 125-128.

[5] Tomski L., Szmidla J., Drgania swobodne i stateczność układów podanych działaniu obciążenia swoistego, [In:] Drgania swobodne i stateczność obiektów smukłych jako układów liniowych lub nieliniowych, ed. L. Tomski, Wydawnictwo Naukowo-Techniczne, Fundacja „Książka Naukowo-Techniczna, Warszawa 2007.

[6] Kounadis A.N., Giri J., Simitses G.J., Nonlinear stability analysis of an eccentrically loaded two - bar frame, Journal Appl. Mech. Trans. of the ASME 1977, 44, 701-706.

[7] Sophianopoulos D.S., The effect of joint flexibility on the free elastic vibration characteristics of steel plane frames, Journal of Constructional Steel Research 2003, 59, 995-1008.

[8] Kounadis A.N., Static stability analysis of elastically restrained structures under follower forces, Amer., Inst. Aeron. Astr. J. 1980, 18, 4, 473-476.

[9] Rallis N.S., Kounadis A.N., Nonlinear sway - bucking of geometrically imperfect rectangular frames, Ing. Arch. 1985, 55, 90-97.

[10] Evensen D.A., Nonlinear vibrations of beams with various boundary conditions, AIAA Journal $1968,6,2,370-372$

[11] Szmidla J., Drgania własne i stateczność ram płaskich poddanych działaniu obciążenia swoistego, [In:] Drgania swobodne i stateczność układów smukłych poddanych obciążeniu swoistemu, Wydawnictwo Politechniki Częstochowskiej, Częstochowa 2009.

[12] Tomski L., Uzny S., Drgania swobodne i stateczność wspornikowych kolumn geometrycznie nieliniowych poddanych obciążeniu swoistemu, [In:] Drgania swobodne i stateczność obiektów smukłych jako układów liniowych lub nieliniowych, ed. L. Tomski, Wydawnictwo Naukowo-Techniczne, Fundacja „Książka Naukowo-Techniczna”, Warszawa 2007. 